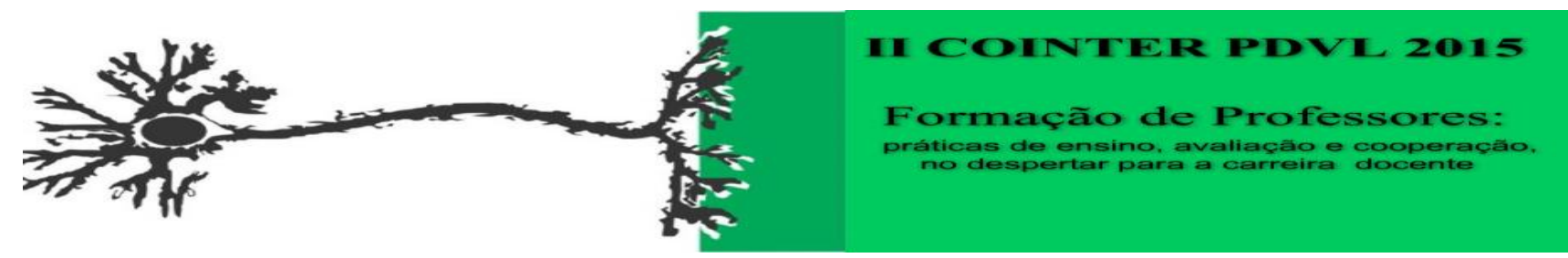

\title{
A QUÍMICA ORGÂNICA EXPLORADA NO ENEM (2011 a 2014) E NA SALA DE AULA: DIFICULDADES DE ENSINO E APRENDIZAGEM
}

\author{
Apresentação: Pôster
}

\begin{abstract}
Danilo Oliveira de Souza ${ }^{1}$; Danúbia Oliveira de Souza ${ }^{2}$; Mirtes Ribeiro de Lira ${ }^{3}$; Bruna Herculano da Silva Bezerra ${ }^{4}$
\end{abstract}

\section{Introdução}

A avaliação é um instrumento relacional que possibilita a qualificação dos diferentes aspectos do currículo e da sala de aula, sendo um ponto de grande complexidade, tornando-se necessário o desenvolvimento de metodologias avaliativas coerentes com os processos de ensino e aprendizagem desenvolvidos. Com isso, o Exame Nacional do Ensino Médio - ENEM é um modelo de seleção de estudantes concebido para avaliar habilidades e competências humanas, isto é, um procedimento seletivo adaptado às exigências dessa nossa sociedade, como aponta Andriola (2011).

Dentre as áreas de conhecimentos avaliados pelo ENEM, encontra-se aQuímica, e de acordo com os PCN's (1999), o Ensino de Química deve possibilitar ao aluno a compreensão tanto de processos químicos em si, quanto da construção de um conhecimento científico em estreita relação com as aplicações tecnológicas e suas implicações ambientais, sociais, políticas e econômicas.Desse modo, o Ensino de Química deve possibilitar o desenvolvimento do senso crítico do estudante, e pensamento químico facilitando o aprendizado associação com as transformações do cotidiano. SegundoSantos e Schnetzler (2000), o conhecimento químico se enquadra nas preocupações com os problemas sociais que afetam o cidadão, os quais impõem posicionamentos quanto às possíveis soluções.

O objetivo deste estudo é analisar o desempenho dos estudantes do terceiro ano do Ensino Médio sobre o conteúdo de Química Orgânica fazendo uma relação com a proposta dos assuntos de

\footnotetext{
${ }^{1}$ Licenciatura em Química, UFPE, danilo.22souza@hotmail.com

${ }^{2}$ Licenciatura em Química, IFPE, danubia.nubia16@hotmail.com

${ }^{3}$ Doutora, em Educação, UFPE, mirtes.lira@upe.br

${ }^{4}$ Doutoranda do PPGEC, UFRPE, bruna.herculano4@gmail.com
} 
Química apresentados no ENEM no período de 2011 a 2014 e em exercícios em sala de aula sobre o respectivo conteúdo.

\section{Fundamentação Teórica}

A química orgânica está presente nos mais diferentes materiais que nos cercam no dia a dia, nesse contexto estabelecer pontes entre o conhecimento químico aprendido na escola e a vida humana é uma das condições essenciais para tornar a aprendizagem mais significativa. Para um ensino de química significativo deve-se interligar os assuntos com a real necessidade humana, possibilitando assim, a resolução de problemas, compreensão dos processos químicos industriais, medicinais, entre outros. Para Vigotsky (2007), o aluno exerce um papel ativo no processo de aprendizagem, por apresentar condições de relacionar o novo conteúdo a seus conhecimentos prévios, e o professor se torna o responsável por criar zonas de desenvolvimento proximal, ou seja, proporciona condições e situações para que o aluno transforme e desenvolva em sua mente um processo cognitivo mais significativo. Com isso, a compreensão a respeito da necessidade de estudar Química é importante para a superação dos obstáculos enfrentados, entendendo e conhecendo a sua abrangência e seu alcance, facilitando as situações problemáticas reais encontradas no cotidiano, no desenvolvimento de competências cognitivas e na construção do sendo crítico. Como mostra Ferreira (2009, p. 5), o estudo de química orgânica tem grande importância pela existência e aplicações de inúmeras substâncias que contem carbono na sua estrutura, e são classificadas em muitos grupos ou funções de acordo com a sua estrutura e propriedades físicas e químicas semelhantes.

\section{Metodologia}

O trabalho configura-se como um estudo de caso (YIN, 2005), no qual foram analisados os cadernos de prova do ENEM dos anos 2011 a 2014, referente às Ciências da Natureza e suas Tecnologias (que é composta de 45 questões, distribuídas entre questões de biologia, física e química), tendo como enfoque a Química. Levando em consideração tais questões e os conteúdos abordados, foi aplicado um exercício de 20 questões objetivas de Química Orgânica a 24 estudantes do terceiro ano do Ensino Médio de uma escola pública estadual localizada no município de Vitória de Santo Antão - PE, com duração de 1 aula $(50 \mathrm{~min})$. Os estudantes responderam questões relacionadas a elemento químico e ligação química (pelo fato de estarem ligados a química orgânica e servirem de suporte para o entendimento do conteúdo), e propriedades da química orgânica. 


\section{Resultados e Discussões}

Com a tabela 1, observamos que os conteúdos de Química encontram-se bastante diluídos atingindo o maior número de quatro questões. Tratando das questões especificamente do conteúdo de Química Orgânica no quadriênio referido, encontra-se, um percentual que varia entre 06\% a 25\%, atingindo o maior percentual no ano de 2013 com 04 questões.

Tabela 1: Quantitativo de questões de Química no ENEM no período de 2011 - 2014. Fonte: Própria

\begin{tabular}{|l|c|c|c|c|}
\hline \multicolumn{1}{|c|}{ CONTEÚDOS DE QUÍMICA } & $\mathbf{2 0 1 1}$ & $\mathbf{2 0 1 2}$ & $\mathbf{2 0 1 3}$ & $\mathbf{2 0 1 4}$ \\
\hline Química Orgânica & $\mathbf{0 1}$ & $\mathbf{0 2}$ & $\mathbf{0 4}$ & $\mathbf{0 2}$ \\
\hline Termodinâmica & 01 & 01 & -- & -- \\
\hline Química Inorgânica & 01 & 01 & 02 & 02 \\
\hline Química Ambiental & 04 & 03 & 02 & 02 \\
\hline Separação de Mistura & 01 & -- & 01 & 02 \\
\hline Solução & 02 & 04 & -- & 02 \\
\hline Eletroquímica & -- & -- & 02 & -- \\
\hline Propriedades Substâncias & 01 & 01 & -- & -- \\
\hline Estequiometria & 01 & 01 & 01 & 03 \\
\hline Ligação e Estrutura Molecular & 01 & 01 & 01 & 02 \\
\hline Radioatividade & -- & 01 & 01 & -- \\
\hline Lei dos Gases & $\mathbf{1 3}$ & $\mathbf{1 5}$ & $\mathbf{1 5}$ & $\mathbf{1 5}$ \\
\hline Total & & -- & 01 & - \\
\hline
\end{tabular}

Com os resultados obtidos atravésda aplicação dos exercícios com 20 questões, envolvendo conteúdos que são necessários para uma boa compreensão dos assuntos de química no Ensino Médio, pode-se observar que os estudantes que participaram não conseguiram obter êxito em relação aos conhecimentos necessários em Química Orgânica para um bom desempenho nas avaliações do ENEM.Portanto devem ser levados em consideração vários fatores, dentre eles: os conteúdos não foram abordados devidamente; não tiveram professores durante o período letivo; desinteresse dos estudantes por não compreender a importância da Química no cotidiano; má 
formação dos professores; e também podemos elencar o fator motivacional na resolução desta pesquisa, entre outros.

Em relação aos acertos e erros do exercício proposto, selecionamos 4 questões das 20, que são referente a duas questões que tiveram maior quantidade de erros, mais especificamente entre 0 e 2 acertos, e duas que tiveram mais acertos entre 10 e 11, são respectivamente: (1) a questão pedia uma avaliação sobre as afirmações propostas, para comprovar a veracidade das mesma, na qual era abordado conhecimento sobre o elemento químico hidrogênio, entretanto como podemos observar, nenhum dos estudantes conseguiram obter êxito nessa questão; (2) questão referente a conhecimento específico sobre quais elementos faziam parte da família dos Halogênios. Esse desconhecimento sobre a referida família, é estranho, até pelo fato de que existe uma função orgânica referente a esta família, no caso, a função orgânica Haleto; (3) a questão referente a cadeia orgânica de função haleto, onde visava a classificação da mesma, tendo em vista as características básicas de cadeias; (4) a questão visava a classificação quanto as características da cadeia envolvendo hidrocarbonetos.

Na tabela 2, referente ao quantitativo de acertos por conteúdos de Química Orgânica, podemos constatar que o número de acertos foi menor que $40 \%$, lembrando que foi aplicado a 24 estudantes, com isso: (1) elementos químicos, que compreendeu6 questões aplicadas, e de 144 acertos esperados, obtiveram 28, totalizandoaproximadamente 19\% de acertos; (2) ligação química, compreendeu 6 questões, e de 144 acertos esperados, obtiveram 36 acertos, totalizando aproximadamente 25\% de acertos; (3) propriedades da química orgânica, compreendeu 8 questões , e de 192 acertos esperados, obtiveram 62 acertos, totalizando $32 \%$.

Um ponto preocupante é sobre o conteúdo elementos químicos, considerado o mais elementar e essencial para se compreender os demais conteúdos de Química, que apresentou um percentual de apenas $19 \%$ de acertos. Estes dados confirmam as dificuldades e o pouco conhecimento dos estudantes sobre notações químicas e tabela periódica, uma vez que o conceito de elemento químico é um dos mais importantes da disciplina podendo ser considerado, conforme Oki (2002) como um conceito estruturante para o desenvolvimento dessa ciência e que serve de base para outros conteúdos com atomística, ligação química, reação química e química orgânica.

Tabela 2: Porcentagem aproximada de acertos referentes a conteúdos aplicados no exercício com 20 questões. Fonte: Própria 


\begin{tabular}{|l|c|}
\hline \multicolumn{1}{|c|}{ CONTEÚDOS } & ACERTOS (24 ESTUDANTES) \\
\hline Elementos Químicos & $19 \%$ \\
\hline Ligação Química & $25 \%$ \\
\hline Propriedades da Química Orgânica & $32 \%$ \\
\hline
\end{tabular}

\section{Conclusões}

Através das análises, podemos indicar que a não solicitação de determinados conteúdos no ENEM pode contribuir para que estes não sejam trabalhados no Ensino Médio.

O baixo rendimento desses estudantes se deve a várias razões, com isso, podemos inferir os seguintes fatores, dentre elas: (1) os conteúdos não foram abordados devidamente; (2)não tiveram professores durante o período letivo, por exemplo, e por esse motivo, uma defasagem nos conteúdos; (3) desinteresse dos estudantes por não compreender a importância da Química no cotidiano; (4) má formação dos professores, dificultando a abordagem dos conteúdos; etc. Desse modo, para que os estudantes estejam realmente preparados, há a necessidade de que os professores trabalhem em sala de aula os conteúdos específicos da Química Orgânica não apenas para obter bons resultados no ENEM, mas também pela importância da aplicação desses conhecimentos no cotidiano.

\section{Referências}

ANDREOLA, W. B. Doze motivos favoráveis àadoção do Exame Nacional do Ensino Médio (ENEM) pelas Instituições Federais de Ensino Superior (IFES). Ensaio: aval. Pol. Públ. Educ., Rio de Janeiro, v. 19, n. 70, p. 107-126, jan./mar. 2011.

BRASIL. Secretaria de Educação Média e Tecnologia, Ministério da Educação. Ciências da Natureza, Matemática e suas Tecnologias. In: Parâmetros Curriculares Nacionais do Ensino Médio, Brasília, 1999.

OKI, M. C. M. O conceito de elemento: da antiguidade a modernidade. Química Nova na Escola. São Paulo, n. 16, p. 21-25, 2002.

SCHNETZLER, R. P.; SANTOS, W. L. P. Educação em Química: compromisso com a cidadania. $2^{\text {a }}$ Ed. Ijuí: Ed. UNIJUÍ, 2000.

VIGOTSKY, L. S. A formação social da mente. São Paulo: Martins Fontes, 2007.

YIN, R. K. Estudo de Caso: planejamento e métodos. 3a . ed. Porto Alegre: Bookman, 2005. 212 p. 